\title{
Process chain for the manufacture of hybrid bearing bushings
}

\author{
Susanne Elisabeth Thürer ${ }^{1}\left(\mathbb{D} \cdot\right.$ Anna Chugreeva $^{2} \cdot$ Norman Heimes $^{2} \cdot$ Johanna Uhe $^{2} \cdot$ Bernd-Arno Behrens $^{2}$. \\ Hans Jürgen Maier ${ }^{1}$. Christian Klose ${ }^{1}$
}

Received: 14 December 2020 / Accepted: 1 February 2021

(C) The Author(s) 2021, corrected publication 2021

\begin{abstract}
The current study presents a novel Tailored Forming process chain developed for the production of hybrid bearing bushings. In a first step, semi-finished products in the form of locally reinforced hollow profiles were produced using a new co-extrusion process. For this purpose, a modular tool concept was developed in which a steel tube made of a case-hardening steel, either C15 (AISI 1015) or 20MnCr5 (AISI 5120), is fed laterally into the tool. Inside the welding chamber, the steel tube is joined with the extruded aluminum alloy EN AW-6082. In the second step, sections from the compound profiles were formed into hybrid bearing bushings by die forging. In order to set the required forming temperatures for each material—aluminum and steel—simultaneously, a tailored heating strategy was developed, which enabled successful die forging of the hybrid workpiece to the desired bearing bushing geometry. Using either of the case-hardening steels in combination with aluminum, this novel process chain made it possible to produce intact hybrid bearing bushings, which showed both macroscopically and microscopically intimate material contact inside the compound zone.
\end{abstract}

Keywords Tailored forming $\cdot$ Hybrid bulk metal component $\cdot$ Co-extrusion $\cdot$ Die forging

\section{Introduction}

For the aviation and automotive industries, both the reduction of $\mathrm{CO}_{2}$ emissions and the increase in resource efficiency are of major interest and, in order to meet these requirements, lightweight construction and thus, intensive use of light metals for high-performance components is needed [1]. Here, aluminum alloys are usually preferred due to high specific strength and adequate formability. The use of hybrid components represents a promising approach to the integration of aluminum in designs that should be light, but must also endure high loading during service. In sheet metal forming in the automotive industry, such occasionally contradictory design challenges have been met by extensive use of Tailored Blanks. These have enabled sheet metal components to be provided with locally adapted properties. In this way, sheets of different material grades and thicknesses

Susanne Elisabeth Thürer

thuerer@iw.uni-hannover.de

1 Institut für Werkstoffkunde, Leibniz Universität Hannover, Garbsen, Germany

2 Institut für Umformtechnik und Umformmaschinen, Leibniz Universität Hannover, Garbsen, Germany etc. are combined to save mass. With this approach it is also possible to improve crash behavior [2].

The manufacturing of massive hybrid components, however, is not widespread on an industrial scale. It is well known that previously formed near-net-shape components can be joined by friction welding to form relatively simple geometries of the joining surface. In contrast, the bulk metal forming of hybrid components allows the creation of complex joining zones that are adapted to the load conditions of the part. However, further research is needed for establishing this promising approach in industry. As part of the novel concept of Tailored Forming, entire process chains are being developed, which, in a first step, join different bulk materials prior to bulk metal forming. In a second step, a massive forming process such as die forging is used to produce the hybrid component. HERBST et al. have already addressed the significant difference between this method and conventional process chains. In these conventional process chains, the individual near-net shape components are combined only after the forming process or at the end of the process chain [3].

The methods developed within the framework of the Collaborative Research Center (CRC) 1153 "Tailored Forming" are inspired by the production of Tailored Welded Blanks, 
which uses hybrid sheet forming processes. By using different joining processes in Tailored Forming, bi-metal 3D solid components are manufactured, which exhibit locally adapted properties due to their design and materials selection. E.g., the substitution of steel with aluminum will significantly reduce the mass of bulk metal parts, if the functional surface, which undergoes high operating loads, is made of a highstrength and wear-resistant material only, such as hardened steel. An essential aspect of the novel process chain is the common forming step of previously joined hybrid workpieces. In this forming step, the final geometry is achieved and the local microstructure in the joining zone is effected positively by thermomechanical treatment. For a reliable bond, the narrowest possible intermetallic phase seams are aimed for. An example for such a process chain is shown in Fig. 1, which describes the production of a hybrid bearing bushing. This component made of aluminum and steel is considered a demonstrator component for the Tailored Forming technology [4].

\section{State of the art}

\subsection{Manufacturing of hybrid workpieces by co-extrusion}

As already mentioned, the manufacture of hybrid solid semi-finished products by welding is already established, as it is the case with Tailored Blanks. Another option for joining different materials is pressure welding. This process is promising, because the resulting intermetallic phase seam is adequately narrow, and thus negative effects on properties (e.g. tensile strength) can be avoided [6]. Co-extrusion also belongs to the pressure welding processes, which allows the continuous production of hybrid semi-finished products made of at least two different materials [7]. According to the German standard DIN 8593-5, co-extrusion refers to joining by forming [8]. In principle, co-extrusion can be subdivided into two different main types of processes, in which the joining partners are formed either completely or locally. Each of these approaches utilize a different type of extrusion billet:

- Modified billets: In this variant, the reinforcement is located inside the billet. The matrix material as well as the reinforcing element are therefore subjected to the whole extrusion process. This process variant includes the co-extrusion of metal matrix composites. The reinforcing element has been introduced into the billet material previously by metallurgical means, as in the case of an aluminum billet reinforced with dispersed $\mathrm{Al}_{2} \mathrm{O}_{3}$ particles [9]. The use of local reinforcements in the form of single reinforcing elements, i.e. a round bar in the center of the billet, also belongs to this group. The feasibility of the latter method for aluminum alloys as matrix material in particular was already demonstrated by combining aluminum (billet) and titanium (cast round bar) [10].

- Conventional billets: This variant is based on the use of mono-material billets without reinforcement, as these are

\section{design/construction/simulation/quality check}

$20 \mathrm{MnCr} 5$ (AISI 5120)/

C15 (AISI 1015)

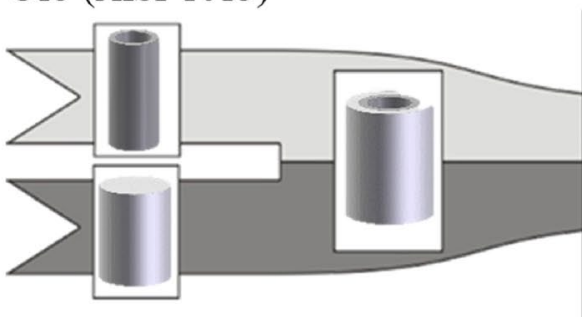

EN AW-6082

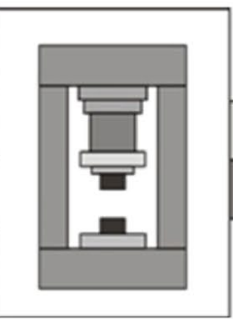

die forging
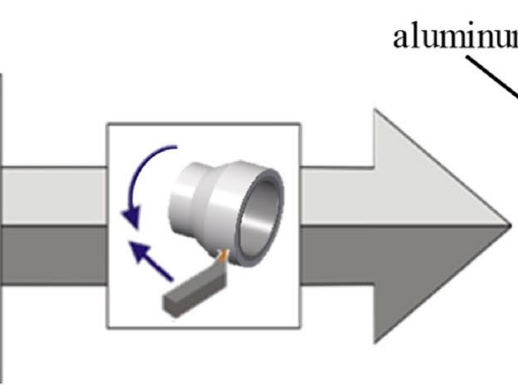

minum
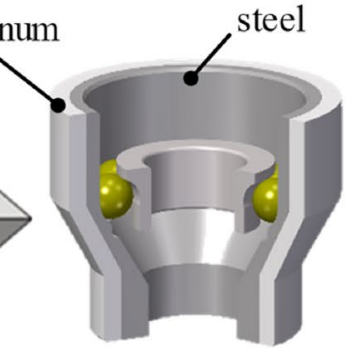

hybrid bearing bushing with locally adapted properties and functions
Fig. 1 Schematic Tailored Forming process chain for the demonstrator component of the hybrid bearing bushing, starting with a Lateral Angular Co-Extrusion (LACE) process for the manufacture of the bi-metal semi-finished products and subsequent forming into the aluminum/steel bulk metal component by die forging; according to [5] 
commonly used in industrial extrusion approaches. The reinforcing element is thus, introduced into the forming zone from the outside and, unlike the matrix material, not deformed plastically [11]. This type of co-extrusion was investigated mainly by combining extruded profiles of light metals with steel and copper wires. The application of modified chamber tools enables the wires to be introduced directly into the forming zone through the mandrel support arms [12]. As a result, the wires are positioned within the longitudinal weld seams (LWS) of the profile [13].

The LACE (Lateral Angular Co-Extrusion) process developed by GRITTNER et al. can be categorized as a coextrusion process using conventional billets. GRITTNER et al. used this process to insert relatively stiff sheets and flat titanium profiles into the forming zone of the tool at an angle of $80^{\circ}-90^{\circ}$ to the extrusion direction. This procedure can be described as a quasi-continuous feeding of the reinforcement into the extrusion process [14]. In earlier studies by the authors, a LACE process in the laboratory scale for the jacketing of round steel bars with an aluminum alloy was developed. The resulting compound profiles consisting of $20 \mathrm{MnCr} 5$ case-hardened steel (1.7147-AISI 5120) and the aluminum alloy EN AW-6082 differed considerably from the intended coaxial arrangement of the two material components, due to specific limitations of the primary tool design [15]. Recent investigations by THÜRER et al. employing a new tool design at near-industrial scale as well as $20 \mathrm{MnCr} 5$ steel tubes as reinforcing elements have already shown that sufficiently coaxial aluminum-steel hollow profiles featuring reinforcement contents of both $14 \mathrm{vol} \%$ and 34 vol\% can be successfully achieved. In addition, shear strengths of up to $58 \mathrm{MPa} \pm 15 \mathrm{MPa}$ were determined on sample segments that included the joining zone, which indicated the presence of a metallurgical bond by adhesion of aluminum to the steel [5]. For the planned subsequent die forging step within the Tailored Forming process chain (compare schematic process chain in Fig. 1), the desired coaxial arrangement of the two materials is indispensable. Furthermore, it is of major interest whether the developed LACE process can be transferred to reinforcements made of other materials and if a subsequent forming of the hybrid semi-finished product can be carried out successfully.

\subsection{Forging of hybrid components}

Depending on the initial state of the workpiece, multi-material forging processes are divided into compound forging and hybrid forging. The first method represents a combination of joining and forging operations in a single process step. Basic application studies of this concept showed that production of a uniform joint is challenging. The joining quality improves with increasing temperature [16]. However, increased formation of the oxide layer at elevated temperatures has a negative effect on the joining zone, and consequently on the joint quality [17]. For complex geometries with locally different strains and non-uniform material distribution, realizing a suitable joint becomes difficult. At this point, the second method (hybrid forging), which involves the utilization of previously joined workpieces, can be advantageous. The investigation of Förster et al. on forging of aluminum enclosed magnesium profiles showed that the joint produced by co-extrusion was maintained after the forming [18]. As demonstrated for bimetal gas turbine discs by Klotz et al. [19], the quality of the joint after forming is largely influenced by workpiece's initial condition. Domblesky et al. conducted forging tests on serially arranged friction welded workpieces that demonstrated good workability. The material flow depends on the load direction (axial and side compression) and material combination. In dissimilar compounds, deformation occurs preferentially in the lower strength material [20].

\section{Materials and methods}

\subsection{Materials}

In the present study, the $\mathrm{AlSi} 1 \mathrm{MgMn}$ aluminum wrought alloy (EN AW-6082) was employed as the matrix material in the co-extrusion experiments. The chemical composition of the aluminum alloy was measured using optical emission spectroscopy (Table 1). This aluminum alloy is one of the more easily formable wrought alloys [7], and thus was chosen for the LACE experiments. The billets were obtained from ST Extruded Products Germany GmbH (Vogt, Germany) and had an outside diameter of $142 \mathrm{~mm}$. They were produced by continuous casting and then homogenized. The composition complies with the specifications in the standard DIN EN 573-3 [21].

Two different steel grades were used for the reinforcing element: The unalloyed case hardening steel C15

Table 1 Chemical composition of the alloy EN AW-6082 in wt \% compared with the specification according to DIN EN 573-3 [21]

\begin{tabular}{|c|c|c|c|c|c|c|c|c|c|}
\hline & $\mathrm{Al}$ & $\mathrm{Si}$ & $\mathrm{Fe}$ & $\mathrm{Cu}$ & Mn & $\mathrm{Mg}$ & $\mathrm{Cr}$ & $\mathrm{Zn}$ & $\mathrm{Ti}$ \\
\hline Sample & balance & $1.30 \pm 0.04$ & $0.20 \pm 0.007$ & $0.08 \pm 0.02$ & $0.76 \pm 0.02$ & $0.86 \pm 0.08$ & $0.02 \pm 0.001$ & $0.05 \pm 0.001$ & $0.02 \pm 0.001$ \\
\hline Standard & - & $0.7-1.3$ & 0.5 & 0.1 & $0.4-1.0$ & $0.6-1.2$ & 0.25 & 0.20 & 0.10 \\
\hline
\end{tabular}


(1.0401-AISI 1015) and the case hardening steel 20MnCr5 (1.7147-AISI 5120), which is alloyed with manganese and chromium. For both LACE experiments, the reinforcements were used in the form of tubes with a length of $660 \mathrm{~mm}$, the outer diameter being $44.5 \mathrm{~mm}$ and the inner diameter $32 \mathrm{~mm}$. Optical emission spectroscopy was applied to identify the actual composition of the steels used (Table 2). Their compositions comply with the respective standard specifications according to DIN EN 10084:2008-06 [22].

\subsection{LACE process for the production of hybrid hollow profiles}

Figure 2a shows a schematic section through the relevant parts of the $10 \mathrm{MN}$ extrusion press with the mounted modular LACE tool, which was developed specifically for the Tailored Forming process chain. Since the LACE process is used to encase a rigid reinforcement with a light metal, a mandrel component was designed, which is held in the tool by three support arms, arranged at an angle of $120^{\circ}$ to each other. The procedure for this specific LACE process has been described recently by THÜRER et al. [5] and
Fig. $2 b$ shows four steps of the simulated material flow of the aluminum. In a first step, the aluminum alloy meets the symmetrically designed inlet, where the material is split into two main metal streams. Then, the two metal streams each flow into pockets milled into the tool cavity (see second step). This prolonged flow into the pockets controls the overall flow of the aluminum alloy in such a way that the steel tube fed from the side is equally enveloped from all sides (see third step). This setup has been established in order to prevent the resulting compound profile from shifting or, even worse, from deforming. The aluminum is deflected and within the tool, the two aluminum streams then flow around the mandrel part, which results in a split into three parallel metal streams. These are then joined again in the welding chamber, while making physical contact with the steel tube (transition from the third to the fourth step). The tube is guided orthogonally to the direction of movement of the ram through the clamping cover and the mandrel part in the tool. In the mentioned fourth step, the compound profile exit the tool through the die. As the previous results by the authors showed [5], this specific tool and process design is capable of ensuring a

Table 2 Chemical compositions of the unalloyed case-hardening steel $\mathrm{C} 15$ and the alloyed case-hardening steel $20 \mathrm{MnCr} 5 \mathrm{in}$ wt $\%$ used for the LACE experiments compared to the specifications stated in the standard DIN EN 10084:2008-06 [22]

\begin{tabular}{|c|c|c|c|c|c|c|c|}
\hline & $\mathrm{Fe}$ & $\mathrm{C}$ & Si max. & $\mathrm{Mn}$ & $P$ max. & $\mathrm{S}$ & $\mathrm{Cr}$ \\
\hline Sample C15 & Balance & $0.177 \pm 0.01$ & $0.262 \pm 0.01$ & $0.578 \pm 0.01$ & $<0.001 \pm 0.01$ & $0.015 \pm 0.01$ & $0.05 \pm 0.01$ \\
\hline Standard C15 & - & $0.12-0.18$ & 0.40 & $0.30-0.60$ & 0.045 & 0.045 & 0.30 \\
\hline Sample 20MnCr5 & Balance & $0.209 \pm 0.01$ & $0.245 \pm 0.01$ & $1.19 \pm 0.01$ & $0.011 \pm 0.01$ & $0.027 \pm 0.01$ & $1.11 \pm 0.01$ \\
\hline Standard $20 \mathrm{MnCr} 5$ & - & $0.17-0.22$ & 0.40 & $1.10-1.40$ & 0.025 & $\leq 0.035$ & $1.00-1.30$ \\
\hline
\end{tabular}

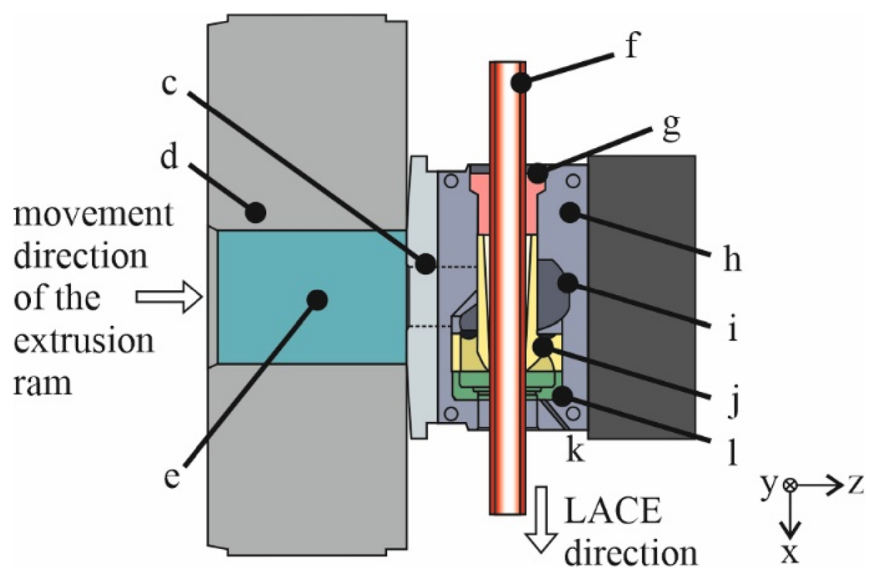

(a)
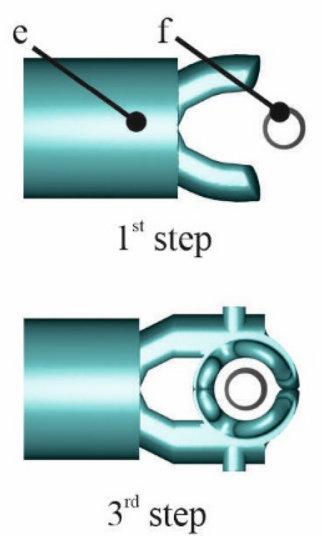

(b)

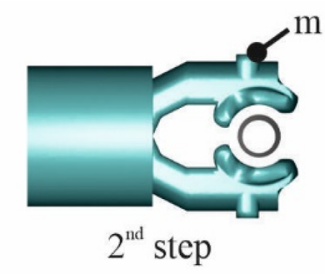

Fig. 2 a Schematic illustration of a lengthwise section plane through the $10 \mathrm{MN}$ extrusion press and the LACE tool, comprising c: bridge, $\mathrm{d}$ : container, e: aluminum billet, f: reinforcement, g: clamping cover, $\mathrm{h}$ : die housing, $\mathrm{i}$ : deflection, $\mathrm{j}$ : mandrel part with three support arms, $\mathrm{k}$ : bore hole for a temperature control by means of a thermocouple,
1: die according to [5]; b simulation of the material flow of the aluminum through the tool with 1st step: splitting in the bridge, 2nd step: deflection and m: filling of the milled pockets, 3rd step: splitting through the support arms of the mandrel part, 4th step: exit through the die; the reinforcement 
mostly coaxial arrangement of the reinforcement inside the compound profile.

The LACE experiments required a modified tool holder for the extrusion press in order to enable an introduction of the reinforcing steel tube into the extrusion process. In this study, a non-heated tool holder was used, which had cavities that allowed for the lateral feeding of reinforcements. The co-extrusion was performed on a $10 \mathrm{MN}$ extrusion press (SMS Meer GmbH, Düsseldorf, Germany). The extrusion ratio of the EN AW-6082 alloy that is used here depends on both the inner diameter of the container $\left(d_{\text {container }}=146 \mathrm{~mm}\right)$ and the opening diameter of the die $\left(d_{\mathrm{die}}=62.7 \mathrm{~mm}\right)$. Additionally, the outer diameter of the steel tube $\left(d_{\text {tube }}=44.5 \mathrm{~mm}\right)$ must be included in the calculation (Eq. 1).

Extrusionratio $=\frac{A_{\text {container }}}{A_{\text {profile }}}=\frac{\pi / 4 \cdot d_{\text {container }}^{2}}{\left(\pi / 4 \cdot d_{\mathrm{die}}^{2}\right)-\left(\pi / 4 \cdot d_{\text {tube }}^{2}\right)}$

For these particular LACE experiments, the extrusion ratio for the aluminum equaled to $11: 1$. In addition, the ratio of the volumes of aluminum and steel in the hybrid profile corresponded to a reinforcement content of $34 \mathrm{vol} \%$. To shorten the process chain, tubes were used instead of round bars for the LACE process. These already had the internal diameter of $32 \mathrm{~mm}$ required for the subsequent die forging process.

Prior to the LACE experiment, the steel tube was ground with 40 grit emery paper and then cleaned with ethanol. In ensured removal of any excess oxides that would curtail the metallurgical bond formation between aluminum and steel upon co-extrusion. Previous numerical investigations have shown that exerting relatively high temperatures as well as long contact times can obtain a metallurgical joint between the joining partners [23]. This transfers to high LACE process temperatures and low extrusion speeds. Hence, the billets were preheated to $530{ }^{\circ} \mathrm{C}$ for $4.5 \mathrm{~h}$. The steel tube was at room temperature at the beginning of the test. The die was preheated to $490{ }^{\circ} \mathrm{C}$ and the container to $440{ }^{\circ} \mathrm{C}$. At the beginning of the LACE process, a ram speed of $1.5 \mathrm{~mm} / \mathrm{s}$ was chosen for upsetting of the billet inside the container. A stepwise decrease of the ram speed was then employed until the desired ram speed of $0.3 \mathrm{~mm} / \mathrm{s}$ for the actual LACE process was achieved. This procedure was intended to counteract and reduce the rapid cooling of the matrix material billet during filling of the die to a minimum.

\subsection{Die forging}

Forming the largest diameter of the bearing bushing shown in Fig. 1 (right) is the main challenge in forging the hybrid semi-finished products manufactured by co-extrusion. In order to achieve sufficient formability, the individual materials need to be heated to their material-specific forging temperatures simultaneously. Therefore, an inhomogeneous temperature distribution within the bi-metal workpieces is necessary. This can be achieved by tailored application of induction heating, where the heat is generated by eddy currents. Due to the skin-effect, which dominates at middle and high operating frequencies, the highest current density is primarily concentrated on the workpiece surface, and thus is subject to the highest thermal input [24]. In the context of steel-aluminum workpieces, this phenomenon can be used to generate heat almost only in the steel component, while the aluminum heating is performed by heat dissipating from the steel. To avoid forming defects (e.g. cracks), the temperature of the steel part should be in the warm or hot forming temperature range (above $550^{\circ} \mathrm{C}$ ). However, the maximum possible temperature for steel is limited by the onset of melting of the aluminum alloy EN AW-6082 (solidus temperature of approx. $\left.580^{\circ} \mathrm{C}[25]\right)$.

Taking the present coaxial workpiece geometry into account that has steel on the inside, an induction heating concept with an internal induction coil was designed (Fig. 3). The heating tests were conducted using a middlefrequency generator TruHeat MF 3040 (TRUMPF GmbH \& Co. KG, Ditzingen, Germany). In order to achieve a high temperature gradient, the maximum power output of $40 \mathrm{~kW}$ was used. The forging experiments were carried out using three heating strategies that differed in heating times. The temperatures were measured at the reference points located inside the center of the steel and aluminum components with thermocouples of type K, as shown in Fig. 3. The resulting temperatures before forging, including a transfer time of $2.5 \mathrm{~s}$ as well as the main generator parameters, are summarized in Table 3.

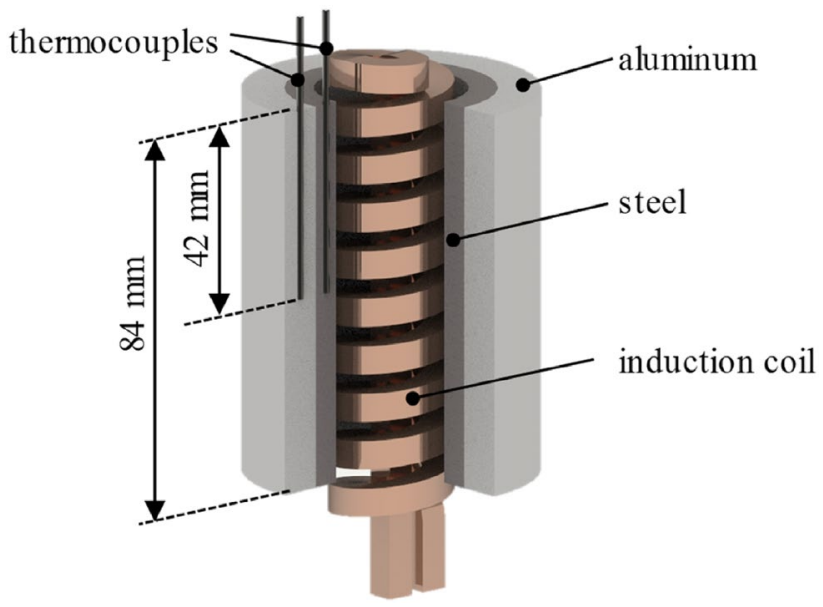

Fig. 3 Concept for induction heating of hollow steel-aluminum workpieces with an internal induction coil and positioning of the thermocouples 
Table 3 Key parameters of the different heating strategies for the die forging experiments

\begin{tabular}{lclll}
\hline Strategy & $\begin{array}{l}\text { Heat- } \\
\text { ing } \\
\text { time, s }\end{array}$ & Generator parameter & $\begin{array}{l}\text { Aluminum } \\
\text { tempera- } \\
\text { ture, }{ }^{\circ} \mathrm{C}\end{array}$ & $\begin{array}{l}\text { Steel } \\
\text { tempera- } \\
\text { ture, }{ }^{\circ} \mathrm{C}\end{array}$ \\
\hline $\mathrm{A}$ & 8 & Power $100 \%(40 \mathrm{~kW})$ & 435 & 520 \\
$\mathrm{~B}$ & 9 & Frequency $20.1 \mathrm{kHz}$ & 480 & 570 \\
$\mathrm{C}$ & 10 & $\begin{array}{l}\text { Capacity } 47.1 \mu \mathrm{F} \\
\text { Transfer time } 2.5 \mathrm{~s}\end{array}$ & 520 & 600 \\
\hline
\end{tabular}

A $40 \mathrm{~kJ}$ screw press of the type Lasco SPR 500 (LASCO Umformtechnik GmbH, Coburg, Germany) was used to carry out single stage forging tests. The corresponding closed-die tool system that was installed in the forging cell is depicted in Fig. 4. The operating principle is described in detail in a previous publication [26]. Before the forming process, the lubricant Berulit 913 (CARL BeCHem GMBH, Hagen, Germany) diluted with water in a ratio of 1:3 was applied to the semi-finished products. For this purpose, they were heated up to a temperature of about $150{ }^{\circ} \mathrm{C}$ in a furnace before being coated with the mixture. After the evaporation of the water, a thin layer of graphite and $\mathrm{MoS}_{2}$ remains on the surface. Subsequently, the coated workpieces were heated up to forging temperature by the described induction heating strategy and then automatically transferred to the forging press with a robot arm. Thus, reproducible process conditions for all forging tests could be achieved.

\subsection{Metallographic characterization of the compound profiles as well as hybrid bearing bushings}

An optical investigation by means of a metallographic characterization was performed on cross-sections from the front end (FE) as well as the back end (BE) of the compound profiles. Thus, deviations in the position of the reinforcement relative to ideal center positions were determined. It must be noted that while similar investigations of the material combination EN AW-6082 and steel $20 \mathrm{MnCr} 5$ have already been presented by the authors in the previous publication [5], the current results were obtained from the particular profiles that were used for subsequent die forging tests and thus, represent an extruded reference condition prior to forging. In addition, sections from extruded hybrid profiles made of EN AW-6082 and C15 steel have not been shown at all before, which enables a direct comparison of the two different material combinations used in this study.

Furthermore, the microstructures of the extruded matrix material was characterized. The location, where all LWS appeared to be macroscopically closed was defined as actual FE for all compound profiles. The position of the BE was reliant on the particular LACE experiment. In case the LACE experiment was stopped before the whole reinforcement was jacketed with aluminum, the part of the compound profile, which was closest to the tool, was examined in cross-section. In contrast, specimens taken from the forged bearing bushings were examined longitudinally in order to

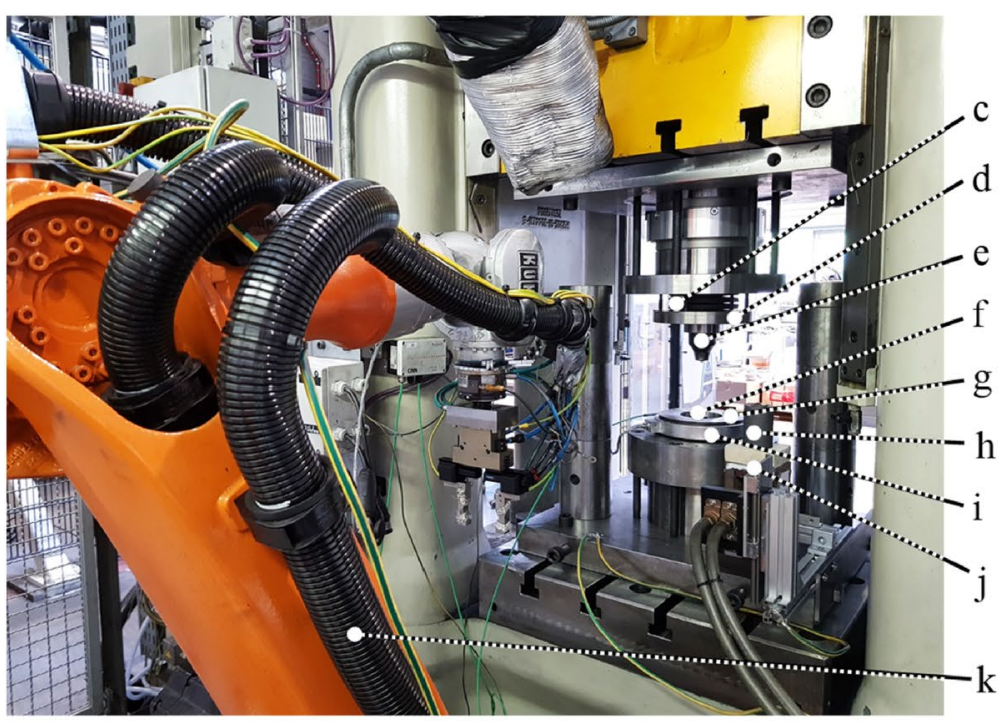

(a)

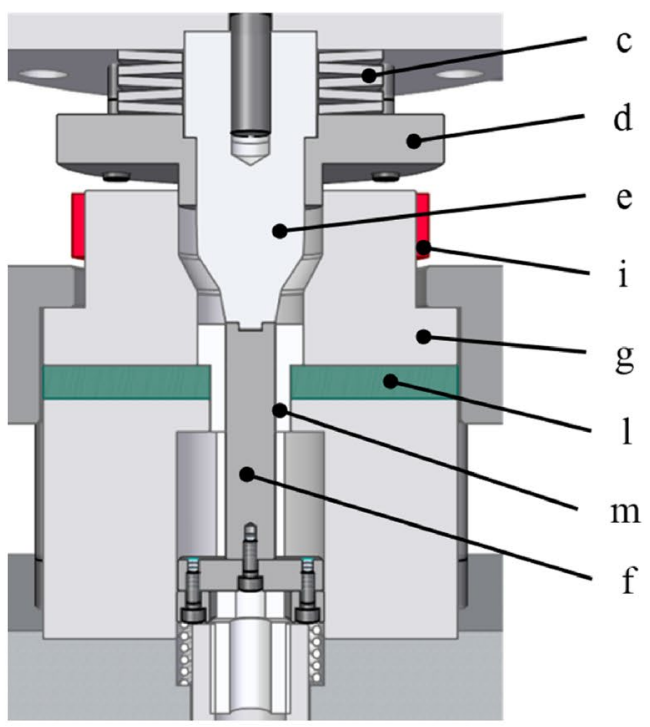

(b)
Fig. 4 Automated forging cell with installed forging tool system for the forging of the bearing bushing (a) and schematic cross-section of the tool system (b) with c: disc springs, d: closure plate, e: punch, f: punch guide, g: forging die, h: hybrid workpiece, i: heating sleeve, $\mathrm{j}$ : induction heating unit, $\mathrm{k}$ : handling robot, $\mathrm{l}$ : insulation plate, $\mathrm{m}$ : ejector 
characterize the modification of the joint zone after forming in both the low and high deformation regions.

For all macro- and microstructural examinations of the bi-metal workpieces, the specimens were prepared metallographically. To contrast the secondary precipitates present within the aluminum alloy, the samples were treated with an etching solution consisting of $\mathrm{HF}$ and $\mathrm{H}_{2} \mathrm{SO}_{4}$. Both case-hardening steels were etched with Nital, to compare the microstructures before and after forming.

\section{Results}

\subsection{Procedure of the LACE Process}

The relevant LACE process parameters such as ram force as well as ram speed were recorded. Figure 5 shows typical force-time curves of two experiments with an extrusion ratio of 11:1 using EN AW-6082 as matrix material and tubes consisting of $\mathrm{C} 15$ (a) or $20 \mathrm{MnCr} 5$ (b) as reinforcing elements. A process-related cooling of the tool caused by the use of a non-heated holder during the LACE experiment was determined via the thermocouple positioned inside the die, near the bearing surface. To counteract this cooling, significantly faster ram speeds were chosen at the beginning of the process. Initially, a ram speed of $1.5 \mathrm{~mm} / \mathrm{s}$ was used in order to upset the billet and fill the tool relatively quickly. As shown in Fig. 5a, b, the ram force rapidly increased until at plateau at around $2.6 \mathrm{MN}$ was reached. After this plateau of the first step, the ram speed was reduced to $0.5 \mathrm{~mm} / \mathrm{s}$. As the filling process progressed (second and third step), the ram force continued to increase. The target ram speed of $0.3 \mathrm{~mm} / \mathrm{s}$ for the main LACE experiment was set after reaching $6 \mathrm{MN}(\mathrm{C} 15)$ and $7 \mathrm{MN}(20 \mathrm{MnCr})$ respectively, reflected by a short drop in force (Fig. 5). Subsequently, the ram force increased continuously to a maximum value of $\approx 8.2 \mathrm{MN}$ (C15) or $\approx 8.0 \mathrm{MN}$ (20MnCr5), at which point (fourth step) the hybrid profile exited the LACE extrusion die. At this point, the ram force did not drop, but increased to $\approx 9.0 \mathrm{MN}$ (C15) and $\approx 8.8 \mathrm{MN}$ (20MnCr5).

Figure 6 shows exemplarily a longitudinal section through the hybrid hollow profile made of EN AW-6082 and $20 \mathrm{MnCr} 5$. Semi-finished products for the die forging process were later produced by sawing and turning the compound profiles. Under macroscopic visual inspection, there seems to be a largely coaxial arrangement of the reinforcing element and the aluminum jacket. The positions of the crosssections that were extracted for closer examination FE and $\mathrm{BE}$ are marked with blue dotted lines. During the separation of the compound profiles from the tool, cooling lubricant partially leaked between the joining partners in the case of the profiles with EN AW-6082 and C15. In the case of the profiles made of EN AW-6082 and 20MnCr5 this could not be detected.

The cross-sections taken from FE and BE of the compound profile (having a total length of $215 \mathrm{~mm}$ ) of the material combination EN AW-6082 and C15 are shown in Fig. 7a, b. In comparison, Fig. 7c, d show the cross-sections of the $\mathrm{FE}$ and $\mathrm{BE}$ of the compound profile with the material combination of EN AW-6082 and 20MnCr5 (total length of $480 \mathrm{~mm}$ ). All cross-sections had an almost circular geometry. Deviations from the intended diameter of the aluminum jacket were found for both profile variants. While the deviation was the same over the entire profile length for $20 \mathrm{MnCr} 5$, a change in values was determined for the profile with $\mathrm{C} 15$ (see Table 4).

These deviations in diameter indicate that the material flow of the aluminum in the tool has not yet been fully adjusted by the milled pockets. As a result, a higher wall thickness of the aluminum jacket can be observed on the side with LWS 3 . Thus, the coaxial arrangement of the steel tube is not ideal. In the material combination with $\mathrm{C} 15$, the desired position was approximately achieved at the beginning (see Fig. 7a). However, this changed over the profile length (see BE in Fig. 7b), hence an influence of the aluminum flow on the reinforcing element in the $\mathrm{x}$-direction must be assumed. For the profile with $20 \mathrm{MnCr} 5$, the offset of the tube from FE (see Fig. 7c) towards the BE (see Fig. 7d) decreased. Further investigations on the influence of the steel grade on the material flow of the matrix material are still pending. The fact that this is not yet ideal is evident from the angle between the LWS. The position of the LWS did not quite correspond to the expected position in all specimens. In particular, LWS no. 3 was tilted away from the recipient in the z-direction. In addition, the angle between LWS no. 4 and no. 2 was typically lower than the expected $120^{\circ}$, with all samples having an angle of about $105^{\circ}$ between LWS nos. 2 and 4 instead.

Deviations of the reinforcement from the ideal coaxial position can be explained in both cases ( 15 and $20 \mathrm{MnCr} 5$ ) by the initial position of the tube inside the tool. The reinforcing element is guided through the mandrel. In order to prevent the tube from getting jammed in the mandrel, the outer diameter of the tube was chosen slightly smaller than the opening of the mandrel, after which the steel tube enters the welding chamber and comes into contact with the matrix material. In contrast to the work of GRITTNER et al. [14], where no offset was possible because a titanium sheet was used as external reinforcement, in the LACE process described here an offset of up to $1.0 \%$ is possible due to the diameter tolerances between tube and mandrel part. The coaxial arrangement of the two joining partners was achieved by turning, which is indicated in Fig. 7 by the white dashed line in the aluminum. For this purpose, the semi-finished products were clamped inside 


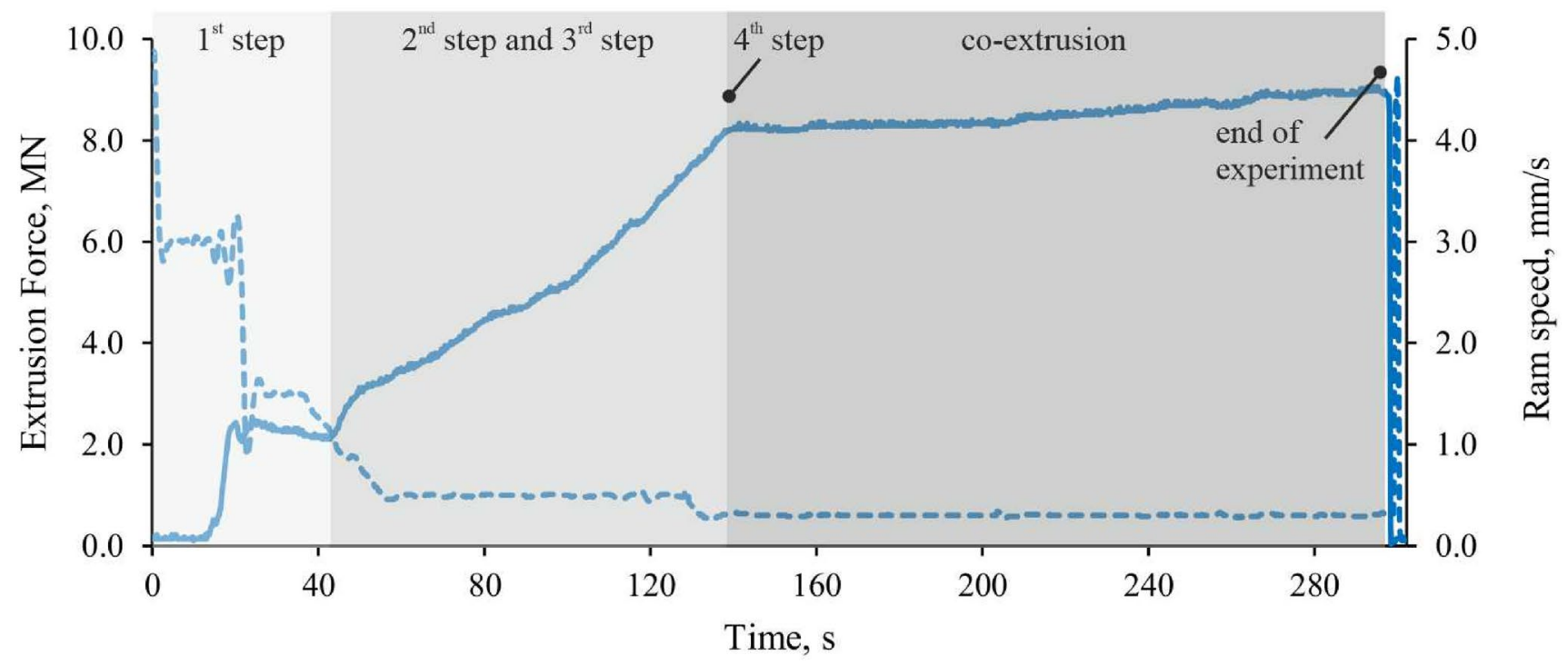

Extrusion force C15 -

(a)

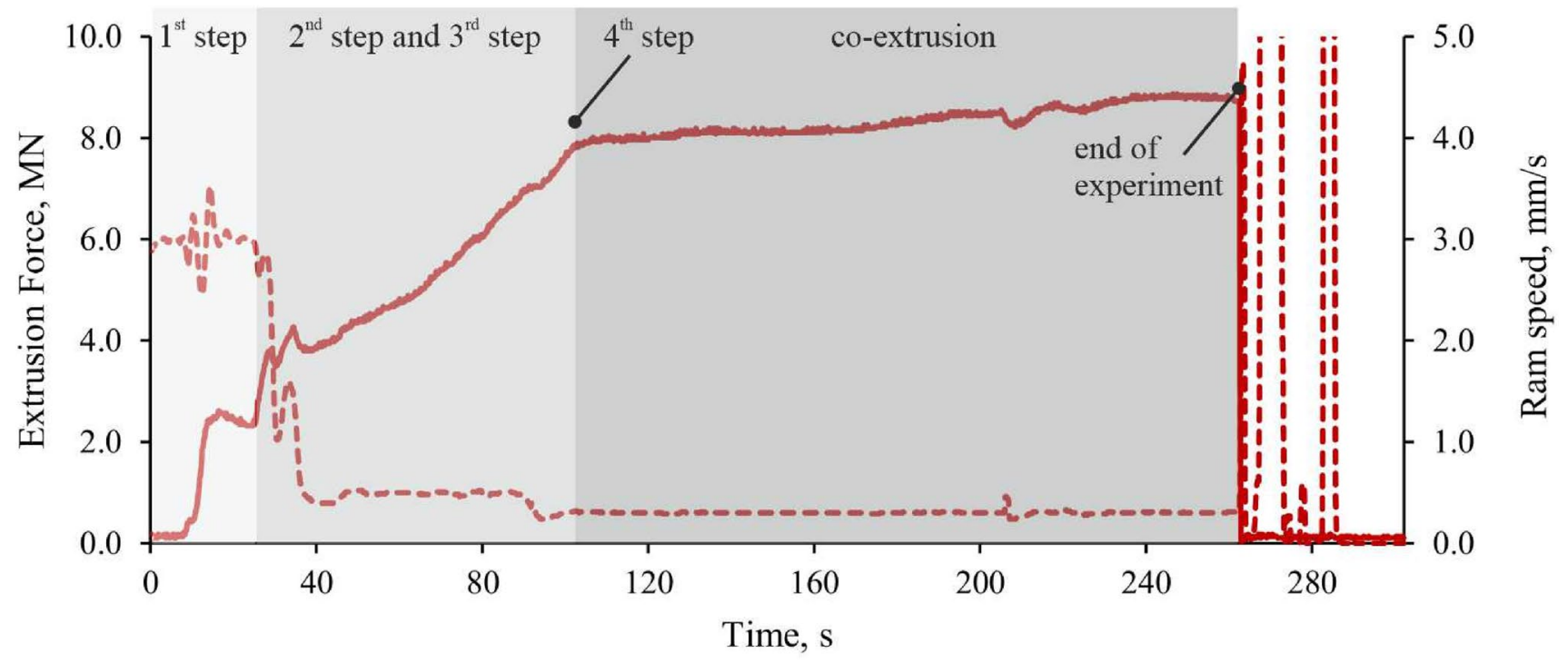

Extrusion force $20 \mathrm{MnCr} 5$

Ram speed 20MnCr5

(b)

Fig. 5 Progression of the ram force during the course of the LACE experiments with the material combination (a) EN AW-6082/C15 and (b) EN AW-6082/20MnCr5; both with an extrusion ratio of 11:1 and adaptions of the particularly adjusted ram speed

the bore of the steel and the aluminum was machined to achieve fully coaxial cylindrical surfaces on the outer diameters of both the steel tube and the aluminum jacket. In the case of the compound profiles with $\mathrm{C} 15$, a maximum of $1.5 \mathrm{~mm}$ of aluminum was removed in diameter. In the case of $20 \mathrm{MnCr} 5$, up to $2 \mathrm{~mm}$ of aluminum were turned.

In addition to the variation of the shape of the supplied reinforcements (e.g. rods, tubes), the successful variation of 


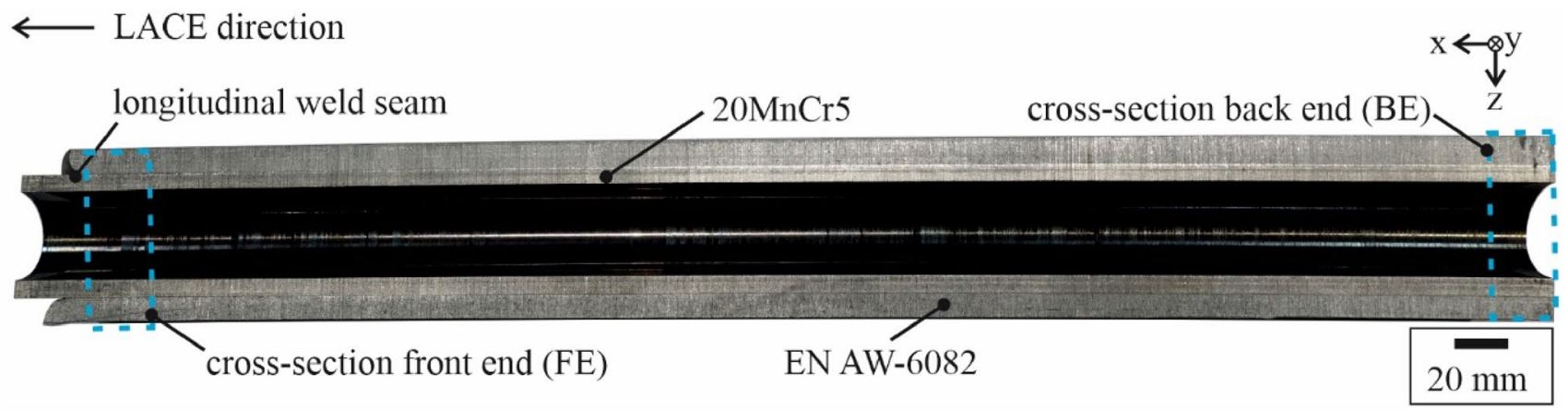

Fig. 6 Longitudinal macroscopic section through the plane of symmetry of a hybrid hollow profile consisting of EN AW-6082/20MnCr5

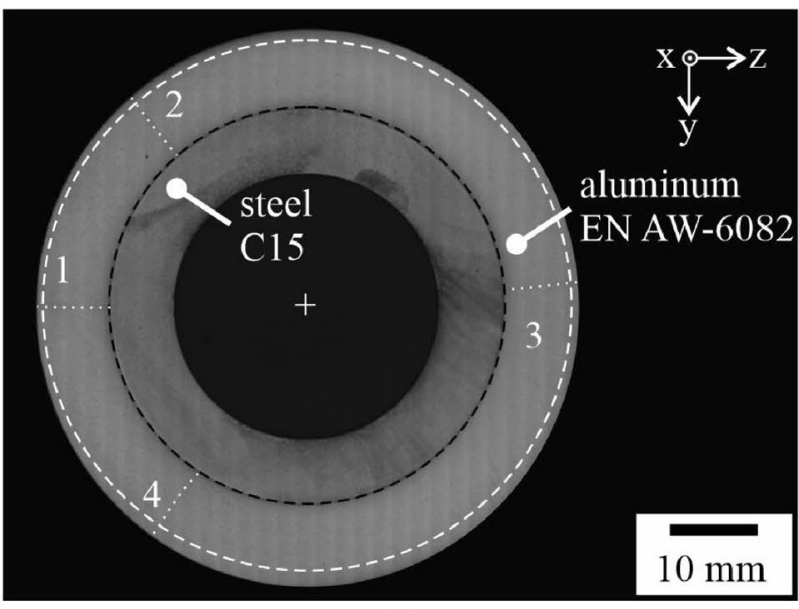

(a)

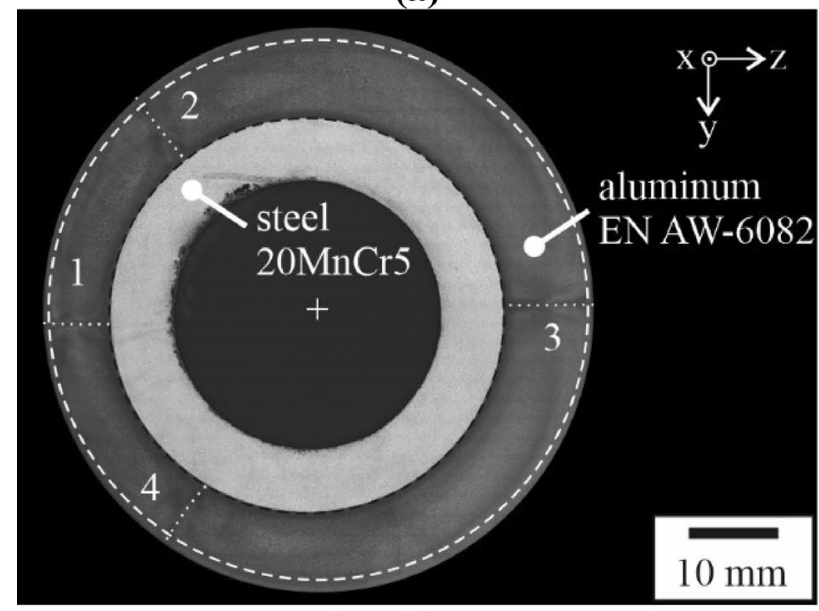

(c)

Fig. 7 Cross-sections extracted from a FE and $\mathbf{b} \mathrm{BE}$ of a compound profile consisting of EN AW-6082/C15; c FE and d BE of a compound profile made of EN AW-6082/20MnCr5; the position of the

the material spectrum is also of interest for a wide range of applications of the LACE process in order to be able to adapt the material to the load case in the future. In this study, C15 and $20 \mathrm{MnCr} 5$ reinforcements were successfully jacketed

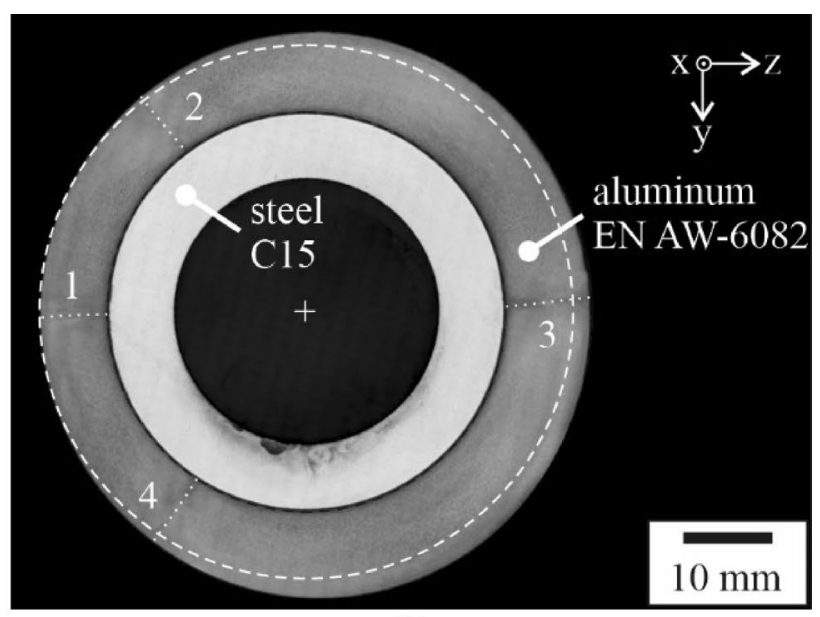

(b)

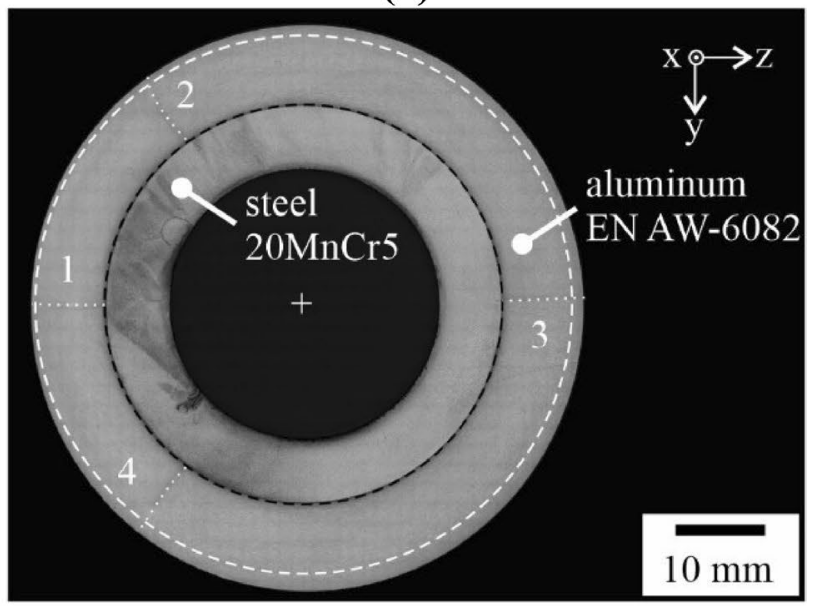

(d)

LWS is highlighted by dotted lines; black dashed lines highlight the outer contour of the steel tube; white dashed lines highlight the outer contour of the aluminum after turning; etching: $\mathrm{HF} / \mathrm{H}_{2} \mathrm{SO}_{4}$ mixture

with the aluminum alloy EN AW-6082. An influence of the steel grade on the parameters of the LACE process and the positioning accuracy of the reinforcement in the compound profile was not found. Upon removing the profile with $\mathrm{C} 15$ 
Table 4 Actual dimensions of the $\mathrm{FE}$ and $\mathrm{BE}$ of compound profiles consisting of EN AW-6082/C15 and EN AW-6082/20MnCr5

\begin{tabular}{llllll}
\hline & \multicolumn{2}{l}{ EN AW-6082/C15 } & & \multicolumn{2}{l}{ EN AW-6082/20MnCr5 } \\
\cline { 2 - 3 } & FE & BE & & FE & BE \\
\hline$d_{\text {z-direction }}, \mathrm{mm}$ & 62.0 & 62.5 & & 62.1 & 62.1 \\
deviation of $d_{\text {z-direction }}, \%$ & -0.5 & -0.3 & & -0.4 & -0.4 \\
$d_{\text {y-direction }}, \mathrm{mm}$ & 63.7 & 64.3 & & 63.5 & 63.5 \\
deviation of $d_{\text {y-direction }}, \%$ & 1.6 & 2.5 & & 1.9 & 1.9 \\
offset in z-direction, mm & - & 0.8 & & 1.3 & 0.3 \\
deviation offset in z-direction, $\%$ & - & -1.2 & & -2.5 & -0.5 \\
offset in y-direction, mm & 0.2 & 0.4 & & 0.8 & 0.1 \\
deviation offset in y-direction, $\%$ & -0.3 & -0.6 & & 1.3 & -0.1 \\
angle between LWS no. 2 and no. 4, ${ }^{\circ}$ & 105 & 105 & & 105 & 105 \\
\hline
\end{tabular}

from the tool, cooling lubricant leaked between the joining partners. It can therefore be assumed that no complete metallurgical bond was present here. Such a behavior was not detected in any compound profile with $20 \mathrm{MnCr} 5$.

\subsection{Die forging}

The hybrid bearing bushings forged with different temperature profiles resulting from the parameters given in Table 3 are shown in Fig. 8. Other parameters of the forging process were the same for all investigated cases. With heating strategy A (8 s of heating), a vertical crack along the whole length of the component occurred as a result of an insufficient formability of the steel part, whose actual temperature was well below usual forming temperature in this test. The most critical temperature is not present in the center of the steel part but at the joining zone, where steel and aluminum have an almost equal temperature under $450{ }^{\circ} \mathrm{C}$. Thus, the steel part had insufficient formability and failed during the forming process. Blue discoloration of the fractured surface relates to the blue-brittleness effect caused by dynamic strain aging at low forming temperatures [27]. This behavior is accompanied by maximum ultimate strength and minimum ductility, which can lead to premature material failure even at low strain. Different from strategy A, the critical temperature threshold for steel forming was exceeded with strategy B ( 9 s of heating) even at the joining zone. Consequently, the bearing bushing could be successfully formed without any macroscopic defects. It should be mentioned that changing the temperature field by applying a different heating strategy could also have an impact on e. g. the local tribological conditions, strain and strain rates even if the stroke kinematics were kept unchanged. Damage initiation in hot forming can be affected by the prevailing strain rate as discussed in [28]. Thus, the success of the process setup is determined not only by the temperature fields of both workpieces, but represents a result of the entirety of the process conditions of heating strategy B. In order to the determine process stability limits increased temperatures of the steel component, strategy $\mathrm{C}$ employing a heating time of $10 \mathrm{~s}$ was investigated. However, the aluminum component reached a temperature above $500{ }^{\circ} \mathrm{C}$ and thus, failed on the outside diameter due to hot cracking.

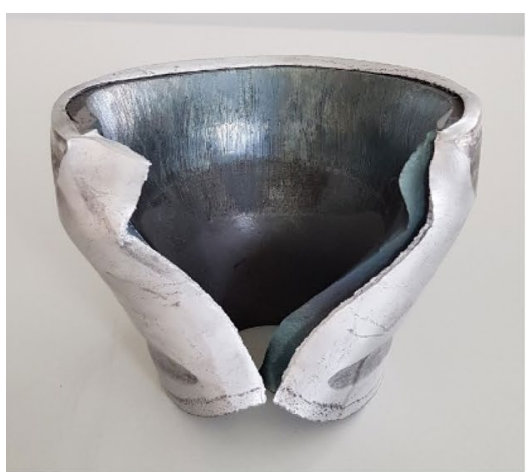

(a)

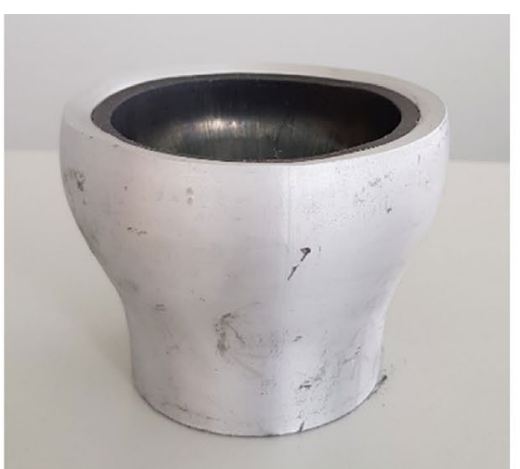

(b)

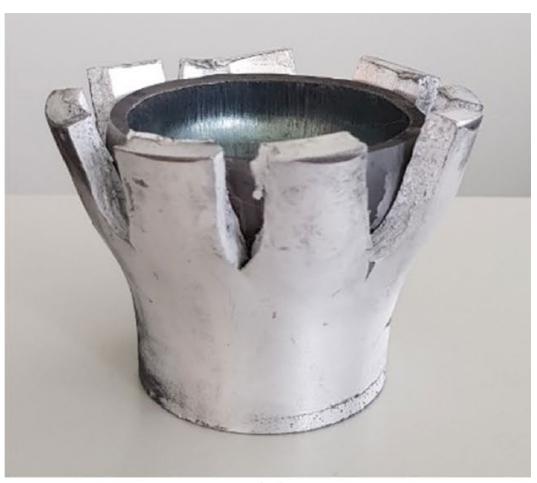

(c)

Fig. 8 Hybrid bearing bushings made of EN AW-6082/20MnCr5 formed with heating strategy A (a), heating strategy B (b) and heating strategy $\mathrm{C}(\mathbf{c})$ 


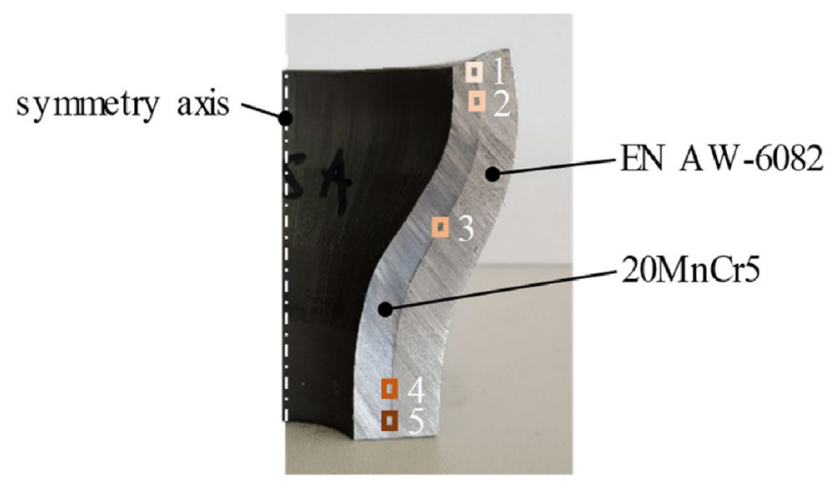

Fig. 9 Material distribution in the longitudinal section after forging according to heating strategy $\mathrm{B}$; with positions $1-5$ used for the microstructural investigations

Figure 9 represents the material distribution of a bearing bushing successfully forged using heating strategy B. There are three main characteristic areas: the largest diameter, the inclination and the smallest diameter. Metallographic examinations were carried out on one part consisting of EN AW$6082 / 20 \mathrm{MnCr} 5$ and on two parts made of EN AW-6082/C15. Representative micrographs recorded at characteristic points along the joining zone are shown in Fig. 10 and marked from 1 to 5 .

All micrographs from the inclination area show a sufficient bond. A separation of the joining partners can be detected at both ends of the specimen with EN AW$6082 / 20 \mathrm{MnCr} 5$ (Fig. 10a). The gap size is up to $60 \mu \mathrm{m}$ at position 1 and about $20 \mu \mathrm{m}$ at position 5 . In the lower part with the smaller diameter of the hybrid bushing, the separation took place particularly within the aluminum alloy, therefore, some aluminum remains adhered to the steel. This indicates that the bond that was established during extrusion did not fail, but crack formation occurred inside the softer aluminum alloy during forging.

Similarly, the bond in the lower part of both specimens consisting of EN AW-6082 and C15 did not failed during the deformation (Fig. 10b, c). In the upper part of specimen 2, the joining zone obtained a wavy morphology after forming (Fig. 10b). The gap size at position 1 is between 30 and $50 \mu \mathrm{m}$. There are some particles of steel visible on the aluminum side of the gap. In contrast to specimen 2, specimen 3 shows a complete joint along the whole interface zone except for a couple of air inclusions as can be seen at position 1 (Fig. 10c). All micrographs of the samples having the material combination EN AW-6082/C15 demonstrate an extremely deformed pearlite phase on the steel side close to the joining zone. This effect appears after forming and can be explained by the influence of the inhomogeneous heating strategy and specific material flow in the joining zone.

\section{Discussion}

In the present study, the LACE process for the production of hollow compound profiles was successfully performed using a reinforcing element made of $\mathrm{C} 15$. Furthermore, as in a previous work [5], compound profiles were made of EN AW-6082 and 20MnCr5. It was possible to subsequently form the bi-metal semi-finished products, which had a reinforcement content of $34 \mathrm{vol} \%$, into hybrid bearing bushings by die forging.

The deviations of the tube position from the ideal position could be explained by the tolerance of the tube outside diameter to the mandrel part [5]. Process-related deviations of the ideal position from the actual position of reinforcements in compound profiles have also been described for wire reinforcements [28]. However, the deviations in this work were above $1.0 \%$, indicating that the aluminum flow in the tool is still uneven and needs further adjustment in order to ensure a fully coaxial arrangement of the tube in the matrix. Also, the fact that there was a clear difference between the sample from $\mathrm{FE}$ and $\mathrm{BE}$ of the profile indicates that the flow of aluminum changes during the process in $\mathrm{x}$-direction. Whether these semi-finished products can be successfully formed in the planned Tailored Forming process chain, was not considered in the previous publication [5].

In this study, it could be shown that a compensation of the misalignment of the different compound profiles by turning off the aluminum jacketing is successful. The semifinished products could thus be successfully applied in the Tailored Forming process chain. The reinforcement content of $34 \mathrm{vol} \%$ used here is within the range of $20 \mathrm{vol} \%$ and 50 vol\% mentioned by WeIDENMANN, which he declared relevant for the intended applications in the aviation and automotive industries [13]. This is due to the feeding of rigid reinforcing elements, so that no elaborate combination of externally fed reinforcement with modified billets had to be used. In addition to the reinforcement content, it is also an advantage here that the LACE process enables the continuous production of semi-finished products consisting of aluminum and steel. It can be assumed that this is achieved not only by friction and form fit connection, but also metallurgically [5]. The quality of the joint zone prior to extrusion is essential for the quality of the joint in the compound profile. The better the contact between the materials before the composite extrusion process, the better the joint zone in the compound profile can become [29]. In principle, this can be assumed for all forming processes, and therefore the production of the semi-finished products from aluminum and steel shown here is advantageous for the process chain. By simply shrinking aluminum onto steel, for example, the individual semi-finished products would have to be manufactured and such a metallurgical bond would not be possible. Further 

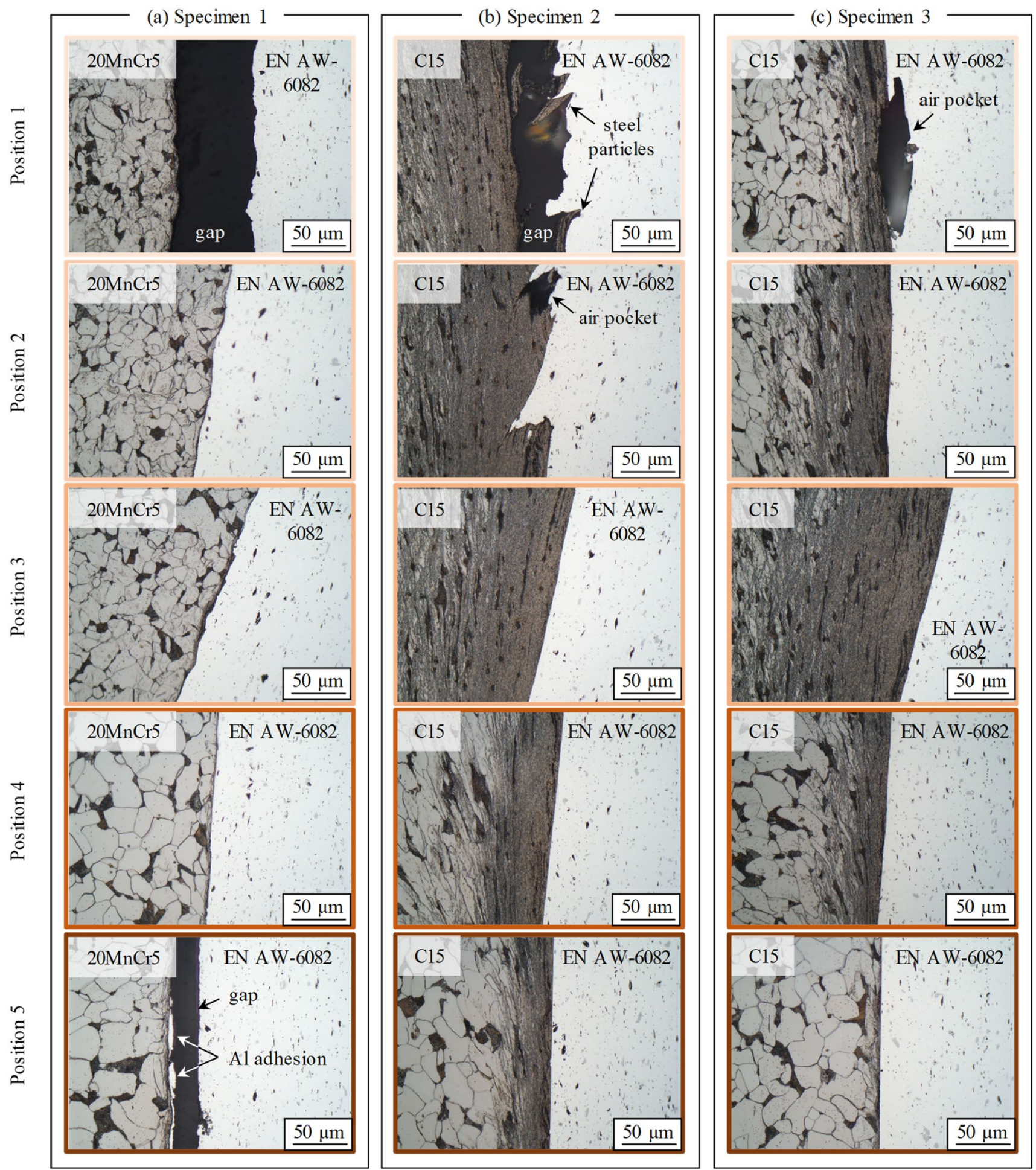

Fig. 10 Micrographs of the joining zone after forging in the longitudinal section: EN AW-6082 and 20MnCr5 (a); EN AW-6082 and C15 (b) and (c); Nital etching

investigations into the formation of the compound between C15 steel and aluminum as well as the resulting mechanical properties must be carried out in the future.
The subsequent forging process causes an enlargement of the joining zone in the upper part of the bearing bushing. Compared to the initial geometry, the inner diameter of the workpiece undergoes a high radial expansion from $32 \mathrm{~mm}$ to 
$64 \mathrm{~mm}$ during forming. Due to the specific material flow and impact of the axial forging load, a local separation during the forming cannot be avoided. The load conditions have a most decisive influence on the stability of the bond [30]. As shown in the examples presented above, the critical regions were located at the ends of the bearing bushing. However, it must be mentioned that a complete die filling was not achieved in the current forging experiments for technical reasons, since this would require further adaptation of the tool. If the compound material were to be fully enclosed in the forging die, the local separations could be eliminated by means of compressive stresses as a result of radial reaction forces between the workpiece and the forging die [31]. The presented process is also appropriate to produce a particular bond by analogy with the compound forging, as was shown in previous investigations [32]. If the advantages of composite and hybrid forging are combined, whereby the connection is maintained in particular by the pre-joined workpieces as well as those newly created at other interfaces, the achievement of sufficient connection properties can be expected.

\section{Conclusions and outlook}

The current paper shows the potential for the production of hybrid bearing bushings by means of Tailored Forming. The main results can be summarized as follows:

- The LACE process according to [5] on an industrial scale was successfully transferred for the quasi-continuous production of hybrid hollow profiles consisting of the aluminum alloy EN AW-6082 and the case-hardening steel $\mathrm{C} 15$. This material combination also showed that the planned coaxial arrangement was almost achieved. An influence of the steel grade on the LACE process itself was not determined and the material spectrum of the LACE process was increased.

- It was possible to develop a heating strategy that enables die forging of the hybrid semi-finished products. The temperature in the joining zone is decisive for failurefree steel forming. To prevent brittleness effects of the steel and at the same time a failure of the aluminum, a temperature range between $450{ }^{\circ} \mathrm{C}$ and $500{ }^{\circ} \mathrm{C}$ should be selected. A heat-up time of $9 \mathrm{~s}$ successfully led to the forming into hybrid bearing bushings.

- Microscopic examinations in longitudinal sections have shown that the quality of the joints at the ends of the bearing bushing was unstable. In the inclination area, there was a continuous joint zone.

While the microstructural investigations in the present study demonstrate the feasibility of the process chain, the bonding area of these samples in particular must be examined with higher detail in the future in order to further refine the process parameters to be able to fully exploit the potential of the LACE process. It has been shown that the joint may not have been formed continuously with $\mathrm{C} 15$. Since this problem did not exist with $20 \mathrm{MnCr} 5$, the influence of the material combination on the bond formation should be further investigated using LACE. In future studies, the coaxial arrangement of the materials in the semi-finished products has to be improved by modifying the LACE tool. Complete filling of the mold should then enable uniform bonding of the components over the entire bearing bushing during forging.

Acknowledgements The results presented were obtained within the subprojects A1 "Influence of local microstructure on the formability of extruded composite profiles" and B2 "Die forging of coaxially arranged hybrid workpieces" of the Collaborative Research Center 1153 "Process chain to produce hybrid high performance components by Tailored Forming"-252662854, which is supported by the German Research Foundation (DFG).

Funding Open Access funding enabled and organized by Projekt DEAL. This study was funded by the Deutsche Forschungsgemeinschaft (DFG, German Research Foundation) — CRC 1153 - 252662854, subproject A1 and subproject B2. The authors gratefully acknowledge DFG's financial support.

\section{Compliance with ethical standards}

Conflict of interest The authors declare no conflict of interest.

Open Access This article is licensed under a Creative Commons Attribution 4.0 International License, which permits use, sharing, adaptation, distribution and reproduction in any medium or format, as long as you give appropriate credit to the original author(s) and the source, provide a link to the Creative Commons licence, and indicate if changes were made. The images or other third party material in this article are included in the article's Creative Commons licence, unless indicated otherwise in a credit line to the material. If material is not included in the article's Creative Commons licence and your intended use is not permitted by statutory regulation or exceeds the permitted use, you will need to obtain permission directly from the copyright holder. To view a copy of this licence, visit http://creativecommons.org/licenses/by/4.0/.

\section{References}

1. Hirsch $\mathbf{J}$ (2011) Aluminium in innovative lightweight car design. Mater Trans 52(5):818-824

2. Merklein M, Johannes M, Lechner M, Kuppert A (2014) A review on tailored blanks-production, applications and evaluation. J Mater Process Technol 241:151-164

3. Herbst S, Maier HJ, Nürnberger F (2017) Strategies for the heat treatment of steel-aluminium hybrid components. HTM J Heat Treat Mater 73(5):268-282

4. Hwang JI, Coors T, Pape F, Poll G (2019) Simulation of a steelaluminum composite material subjected to rolling contact fatigue. Lubricants 7(12):109 
5. Thürer SE, Peddinghaus J, Heimes N, Bayram FC, Bal B, Uhe J, Behrens B-A, Maier HJ, Klose C (2020) Lateral angular coextrusion: geometrical and mechanical properties of compound profiles. Metals 10(9):1162

6. Agudo L, Jank N, Wagner J, Weber S, Schmaranzer C, Arenholz E, Bruckner E, Hackl H, Pyzalla A (2008) Investigation of microstructure and mechanical properties of steel-aluminium joints produced by metal arc joining. Steel Res Int 79(7):530-535

7. Bauser M, Sauer G, Siegert K (2001) Strangpressen, 2nd edn. Aluminium, Düsseldorf

8. DIN EN 8593-5 (2003) Fertigungsverfahren Fügen, Teil 5: Fügen durch Umformen-Einordnung, Unterteilung, Begriffe

9. Foydl A, Haase M, Khalifa NB, Tekkaya AE (2011) Co-extrusion of discontinuously, non-centric steel-reinforced aluminum. In: AIP conference proceedings, vol 1353(1), Belfast, United Kingdom, pp 443-448

10. Dietrich D, Grittner N, Mehner T, Nickel D, Schaper M, Maier HJ, Lampke T (2014) Microstructural evolution in the bonding zones of co-extruded aluminium/titanium. J Mater Sci 49:2442-2455

11. Kleiner M, Schomäcker M, Schikorra M, Klaus A (2004) Herstellung verbundverstärkter Aluminiumprofile für ultraleichte Tragwerke durch Strangpressen. Materialwiss Werkstofftech 35(7):431-439

12. Pietzka D, Ben Khalifa N, Gerke S, Tekkaya AE (2013) Composite extrusion of thin aluminum profiles with high reinforcing volume. Key Eng Mater 554:801-808

13. Weidenmann KA (2012) Verbundstrangpressen mit modifizierten Kammerwerkzeugen: Werkstofftechnik, Fertigungstechnik, Simulation. KIT Scientific Publishing, Karlsruhe, Fertigungstechnik

14. Grittner N, Striewe B, von Hehl A, Engelhardt M, Klose C, Nürnberger $\mathrm{F}$ (2014) Characterization of the interface of co-extruded asymmetric aluminum-titanium composite profiles. Materialwiss Werkstofftech 45(12):1054-1060

15. Thürer SE, Uhe J, Golovko O, Bonk C, Bouguecha A, Klose C, Behrens BA, Maier HJ (2017) Co-extrusion of semi-finished aluminium-steel compounds. In: AIP conference proceedings, vol 1896(1), Dublin, Ireland, 140002-1-140002-6

16. Kong TF, Chan LC, Lee TC (2009) Experimental study of effects of process parameters in forge-welding bimetallic materials: AISI 316L stainless steel and 6063 aluminium alloy. Strain 45(4):373-379

17. Wohletz S, Groche P (2014) Temperature influence on bond formation in multi-material joining by forging. Procedia Eng 81:2000-2005

18. Förster W, Binotsch C, Awiszus B (2018) Process chain for the production of a bimetal component from $\mathrm{Mg}$ with a complete $\mathrm{Al}$ cladding. Metals 8(2):97
19. Klotz UE, Henderson MB, Wilcock IM, Davies S, Janschek P, Roth M, Gasser P, McColvin G (2005) Manufacture and microstructural characterisation of bimetallic gas turbine discs. Mater Sci Technol 21(2):218-224

20. Domblesky J, Kraft F, Druecke B, Sims B (2006) Welded preforms for forging. J Mater Process Technol 171(1):141-149

21. DIN EN 573-3 (2013) Aluminium und AluminiumlegierungenChemische Zusammensetzung und Form von Halbzeug

22. DIN EN 10084:2008-06 (2008) Einsatzstähle-Technische Lieferbedingungen

23. Behrens BA, Klose C, Thürer SE, Heimes N, Uhe J (2019) Numerical modeling of the development of intermetallic layers between aluminium and steel during co-extrusion. In: AIP Conference proceedings, 2113(1), Vitoria-Gasteiz, Spain, 040029-1-040029-6

24. Radzevich SP (ed) (2019) Advances in gear design and manufacture. CRC, Boca Raton

25. Huang C, Kou S (2004) Liquation cracking in full-penetration AI-Mg-Si welds. Weld J 84(4):111-122

26. Behrens BA, Sokolinskaja V, Chugreeva A, Diefenbach J, Thürer SE, Bohr D (2019) Investigation into the bond strength of the joining zone of compound forged hybrid aluminium-steel bearing bushing. In: AIP Conference proceedings 2113(1), VitoriaGasteiz, Spanien, 040028-1-040028-6

27. Jaske CE (1977) Low-cycle fatigue of AISI 1010 steel at temperatures up to $1200{ }^{\circ} \mathrm{F}\left(649^{\circ} \mathrm{C}\right)$. J Pressure Vessel Technol 99(3):423-443

28. Imran M, Szyndler J, Afzal MJ, Bambach M (2020) Dynamic recrystallization-dependent damage modeling during hot forming. Int J Damage Mech 29(2):335-363

29. Müller K (2003) Grundlagen des Strangpressens. 2. Auflage, Renningen-Malmsheim: Expert-Verlag

30. Binotsch C, Nickel D, Feuerhack A, Awiszus B (2014) Forging of Al-Mg compounds and characterization of interface. Procedia Eng 81:540-545

31. Specker A (2009) Untersuchungen zum gratlosen Gesenkschmieden von Kurbelwellen. PZH Produktionstechnisches Zentrum $\mathrm{GmbH}$, Garbsen

32. Behrens BA, Goldstein R, Chugreeva A (2018) Thermomechanical processing for creating bi-metal bearing bushings. In: Conference proceedings of the thermal processing in motion, Spartanburg, South Carolina, USA, pp 15-21

Publisher's Note Springer Nature remains neutral with regard to jurisdictional claims in published maps and institutional affiliations. 